\title{
A Brief Study of Efficacy of Homoeopathic Medicines in Controlling Tonsillitis in Paediatric Age Group
}

\author{
Dr. Siva Rami Reddy. E \\ BHMS, MD, Ph.D Scholar \\ Sri Ganganagar Homoeopathic Medical College, Hospital and Research Center, \\ Sri Ganganagar, Rajasthan, India
}

\begin{abstract}
A Brief study of efficacy of homoeopathic medicines in controlling tonsillitis in paediatric age group, Sri ganganagar, (Raj) India.

Background: Tonsillitis is one of the most common conditions in childhood with recurrent attacks which will result in sever complication. Homoeopathy is giving better result in treating tonsillitis both in acute and chronic recurrent episodes. The objective were to evaluate the constitutional remedial action in case of Tonsillitis and to analyze group of constitutional remedies effective in the treatment of tonsillitis in Paediatric age group.

Methodology: A hospital based observational study was carried out on Sriganganagar Homoeopathic Medical College, Hospital and Research Center, Sri Ganganagar, Raj. The study group of 30 was selected based on purposive sampling method. This is before and after without control type of experimental study. 30 diagnosed cases were considered. Data collected were analysed and inferred with T test used to calculate.

Result: The overall response of the treatment with the help of 10 Homoeopathic medicines. It was observed that out of 30 patients, 18 (60\%) patient were cured, 10 (33\%) patients improved, 2 (7\%) patients showed no response. This study reflects the predominance of Psoric Miasm in the cases of Tonsillitis. Out of 30 cases, 14 ( 46.67\%) cases were purely Psoric, 13 (43.33\%) cases were Sycosis, 1 (3.33\%) cases were Tubercular, 2 ( $6.67 \%)$ cases were Syphilis.
\end{abstract}

Conclusion: Homoeopathic constitutional remedies are very effective in treating tonsillitis in paediatric age group. There were no side effects during the treatment.

Keywords: Tonsillitis, Constitutional Homoeopathic Medicine, Miasm, Outcome.

\section{Introduction}

Tonsillitis is the inflammation of the pharyngeal tonsils. Along with the pharyngeal tonsils, the adenoids and the lingual tonsils may also get inflamed involve other areas of back of throat including the adenoids and the lingual tonsils. Tonsillitis may be caused due to any viral or bacterial infections or any other immunological factor ${ }^{1}$. It is very common in India. Children are more commonly affected ${ }^{2 .}$ Tonsillitis signifies an acute inflammation of the mucous membrane covering the tonsils; or the inflammation may involve the whole gland and the surrounding tissue ${ }^{3}$.The palatine tonsils consists of paired aggregates of lymphoid tissue. They are located in the pocket formed between the palatoglossus and palatopharyngeus muscles and the overlying folds of mucosa, which make up the anterior and posterior tonsillar pillars. With the lingual tonsils, the adenoids and the diffuse aggregates of pharyngeal submoucosal lymphoid tissue they make up waldeyers ring, a complete circle of lymphoid tissue surrounding the entrance to the gstrointestional and respiratory tracts.

Historically they consist of lymphoid tissue with aggregates of lymphocytes arranged in a follicular manner and embedded in a stoma of connective tissue. The stratified squamous mucosal covering of the tonsils extends irregular convoluted investigations in to the parenchyma forming pits or crypts ${ }^{4}$. Lymphoid tissue of Waldeyer ring is most immunologically active between $4-10$ years of age with a decrease after puberty ${ }^{5}$

Types of Tonsillitis: Acute Tonsillitis: It is the acute inflammation and infection of the faucal tonsil (Palatine tonsils) $^{6}$. Patient presents with sore throat, dysphagia (difficulty swallowing), odynophagia (painful swallowing), foul breath, fever and tender cervical lymph nodes. Swelling may cause mouth breathing, snoring, sleep apnoea. Malaise feeling and letharginess ${ }^{7}$.

Recurrent tonsillitis: In this type of tonsillitis there are multiple episodes of acute tonsillitis in a year?

Chronic tonsillitis: chronic tonsillitis may be caused by repeated attacks of acute tonsillitis in which permanent damage has been done to the tonsil, or it can occur when resolution has been imcomplete ${ }^{8}$. A history of at least 3 to 4 attacks of acute tonsillitis in a year should be present to label it as chronic ${ }^{9}$. Patient presents with chronic sore throat, halitosis, tonsillitis, and cervical nodes are persistently tender ${ }^{7}$.

Chronic Follicular Tonsillitis: usually follows acute or sub acute attacks, and is more common in children between 4 and 15 years $^{10}$. Here tonsillar crypts are full of infected cheesy material which shows on the surface as yellowish spots ${ }^{6}$. 
Complications: Complications are uncommon, but some of the problems that can occur are: i. Peritonsillar abscess: Sometimes the abscess formation occurs with severe throat pain, drooling and fever. The abscesses can spread to the surrounding areas, such as the roof of mouth, neck, chest and lungs. Ii. Swelling of the face and neck: Usually occurs in cases of Chronic tonsillitis and leads to airway obstruction and causes difficulty in breathing and may lead to disturbed sleeping patterns. Iii. Otitis media (Middle ear infection): can also occur in severe cases. Iv. Septicemia/ Blood poisoning:

May also occur in severe cases if bacteria get into bloodstream and multiply. V. Lemierre's syndrome: It is very rare and fatal complication in which bacteria from throat enters into the major veins in neck and travel through bloodstream to lungs, joints and bones. Vi. Glomerulonephritis: It is a very rare complication

Treatment: Tonsillitis can be cured with the help of homoeopathic medicines with permanent restoration of health. Even in many severe cases of Recurrent Tonsillitis where tonsillectomy is advised homoeopathic medicines play a great role and surgical intervention can be avoid ${ }^{11}$. Similia similibus Curentur - let likes be treated with likes, as a system of drug - therapeutics based on the law of similar ${ }^{12}$. Homoeopathy has no sideeffects. In homoeopathy, medicines enhances our resistance to fight and give no chance for recurrence due to reinfection of same bacteria or virus. Herbert Spencer says, "Life is a continuous adjustment of internal relations to external"13.

The earlier the treatment started the speedier and more complete is the cure. In this, the immune power is increased against disease, so that recurrence can surely be avoided. In homoeopathy, medicines are usually selected with mode of onset and character of disease, exciting cause, thirst, sweat, shivering, mental restlessness appetite etc. A well selected remedy quickly supports the body mechanism and clears the complaints at the earliest ${ }^{14}$.This study was conducted with aims to find the efficacy of homoeopathic medicine in controlling tonsillitis in paediatric age group and to assess the influence of Miasm in the cases of tonsillitis.

\section{Materials and Methodology}

This study was conducted on the patients who attended the Out Patient department of Sri ganganagar Homoeopathic Medical College, Hospital and Research Center, Sri ganganagar and the study was undertaken for a period of six months. Detailed case was taken, analysis and evaluation following Homoeopathic principles was done ${ }^{14}$.The potency was selected on the basis of individual susceptibility. The outcomes were an improvement of symptoms recorded in monthly basis individual symptoms which includes any appropriate measures of Coughing, chronic sore throat, halitosis, tonsillitis, and cervical nodes are persistently tender, Swelling may cause mouth breathing, snoring, sleep apnoea. Malaise feeling and lethargies. A number of subgroups, homoeopathic potency, age group, and types of tonsillitis (Acute and Chronic) were analyzed.

Statistical Analysis: Data were presented as proportion and percentage and difference in proportion were analyzed by using $\mathrm{T}$ test.

\section{Result}

Among 30 tonsillitis patients with mean $\pm \mathrm{SD}$, maximum cases were observed in age group of $0-5$ years in $6(20 \%)$ cases, 5 - 10 years in $16(53.33 \%)$ cases, $10-15$ years of age group had $8(26.66 \%)$ cases. Patients were in the male $13(43.33 \%)$ and $17(56.66 \%)$ patients were females. Out of 30 cases $17(56.66 \%)$ were females and $13(43.33 \%)$ were males. In the age group $0-5$ years 2 cases $(6.66 \%)$ males, and 4 cases $(13.33 \%)$ females. In the group $5-10$ years, 8 cases $(26.66 \%)$ males, 8 cases $(26.66 \%)$ females and in the age group 10 - 15 there were 3 cases $(10 \%)$ males, and cases $(16.66 \%)$.Out of randomly selected cases $14(46.66 \%)$ cases suffering for 0 to 1 year, $6(20 \%)$ cases suffering for 1 to 2 years. 7 (23.33\%) cases were suffering for 2 to 3 years, $3(10 \%)$ cases suffering for 3 to 4 years.

Associated symptoms were the symptoms that had no direct relation with the disease but were present in the patients of tonsillitis. It was observed that 9 patients $(30 \%)$ of a tonsillitis had coryza. 9 patients $(30 \%)$ reported of having cough along with the symptoms of tonsillitis. Its was also observed that 3 patients $(10 \%)$ of tonsillitis had a problem of ear ache. Only 3 patients (10\%) reported to have headache. 6 patients (20\%) reported generalized weakness. This study reflects the predominance of Psoric Miasm in the cases of Tonsillitis. Out of 30 cases as a Fundamental miasms Psoric expression was seen in 14 (46.67\%) cases, Sycotic expression was seen in $13(43.33 \%)$ cases, Tubercular expression was seen in 1 case (3.33\%), and syphilitic expression was seen in $2(6.67 \%)$ cases. Out of 30 cases Dominant Miasm Psoric expression was seen in $10(33.33 \%)$ cases, Sycotic expression was seen in $13(43.33 \%)$ cases, and Tubercular expression was seen in 7 (23.33\%) cases.

In the research of Homoeopathic medicines in the treatment of tonsillitis paediatric age group 10 medicines were prescribed to the patients according to the symptoms similarity and the following observations were made. Silicea is the most effective medicine out of the total ten Homoeopathic medicines chosen for the study. Silicea cured 3 patients and 3 got improvement hence it can be concluded that Silicea is more effective. During the study it was found that the next effective medicine for the treatment of tonsillitis is clacarea phosphorica. 1 cases got cured, 3 cases got improved, 1 patients not improved. Phosphorus 1 case got cured, 3 
cases improved, Baryta carbonica 2 cases cured, 1 case improved. Pulsatilla Pratensis 1 case cured, 1 case improved and 1 case not improved. Clacarea Carbonica 1 case cured, 2 cases improved. Sulphur 2 cases improved. Lycopodium Clavatum 1 case cured and 1 case improved. Baryta Iodata 1 case cured.Natrium Muriaticum 1 case cured.The overall response of the treatment with the help 10 homoepathic medicines. It was observed that out of 30 patient, $18(60 \%)$ patients were cured, $10(33 \%)$ patients had improvement, $2(7 \%)$ patients showed no response, 30 patients, $18(60 \%)$ patient were cured, $10(33 \%)$ patients improved, $2(7 \%)$ patients showed no response.

\section{Discussion}

Tonsillitis is the most commonly seen infection among below 15 years of age children. It is one of the most important inflammatory diseases of paediatric age group. A repeated attack leads to chronicity and other systematic complications. The presenting complains may vary from systemic symptoms like fever, malaise, with intolerable throat pain, dysphasia and sore throat. As the age progresses the symptoms and severity decrease. The study was conducted on the patients who attended the Out Patient department at Sriganganagar Homoeopathic Medical college, Hospital and Research Center, Sri Ganganagar. The patients, children of age 1 13 years were selected for the study. Both sexes were included and who belong to different socio economic group were taken as per inclusion criteria. A total of 30 cases were selected. Minimum duration of study was 6 months. The statistical analysis made here is based on the data obtained from 30 cases. This study was conducted to prove the efficiency of the treatment for successful management of tonsillitis and arrive at a constitutional Homoeopathic remedies frequently indicated in such as a condition.

Out of 30 cases silicea was indicated in 6 cases (20\%), phosphorus in 5 cases $(16.66 \%)$, calcarea phosphorica in 4 cases (13.33\%), Baryta carbonica in 3 cases (10\%), Pulsaatilla Pratensis in 3 cases $(10 \%)$, calcarea carbonica in 3 cases $(10 \%)$, Sulphur in 2 cases $(6.66 \%)$ and Lycopodium Clavatum in cases 2 cases $(6.66 \%)$. Other remedies like Baryta Iodata in 1 case $(3.33 \%)$ and Natrium Muriaticum in 1 cases $(3.33 \%)$. Therefore, the final outcome after the treatment was $18(60 \%)$ cases showed improved, $10(33.33 \%)$ cases cured, and $2(6.66 \%)$ cases were not improved. From the analysis of the results obtained it is obvious that the constitutional Homoeopathic drugs are very effective in the treatment of Tonsillitis of Paediatric age Group.

\section{Conclusion}

The research shows that Homoeopathic medicine play an important role in the treatment of tonsillitis in paediatric age group. The study depicts that $60 \%$ of patients got relief from the Homoeopathy medicines and this is not a small number. The most effective remedies during the study were silicea, Calcarea Phosphorica, Phosphorus, Baryta Carbonica, Pulsatilla Pratensis, Calcarea Carbonica, Lycopodium Clavatum, Baryta Iodata, Natrium Muriaticum. There were no side effective during the treatment and it can be concluded that homoeopathic medicines can be help the patient to take a new lease on life.During the study it was observed that in almost all the cases the homoeopathic medicines responded well and the patient not only got rid of the main complaints of Tonsillitis but also got rid of the associated complaints with restoration of health. With the help of use of homoeopathic medicines even surgical intervention was avoided. Thus we can conclude that Homoeopathic medicines used with holistic approach are very effective in treating the cases of recurrent tonsillitis.

[1]. Http://en, wikipedia.org/wiki/Tonsillitis (2015).

\section{Bibliography}

[2]. Ghai O.P., Essentials Pediatrics, 6th Edition, 16 A, Narainall, New Delhi, (2008).

[3]. Quay GH. A monograph of diseases of the nose and throat. New Delhi: B Jain Publishers (P) ltd: 2000. P.171-74,80,81.

[4]. Brown s, Otorhinolaryngology, Head and Neck Surgery.Vol.1. $7^{\text {th }}$ Ed. Hodder Arnold Publications. P.1219,21,24,32.

[5]. Behrman ER, Kligman RM, Jenson HB. Nelson text book of Pediatrics. $17^{\text {th }}$ ed. New Delhi: Elesevier; 2004. 2004. P.1396.

[6]. Dhingra PL. Diseases of ear, nose, throat. $4^{\text {th }}$ ed. New Delhi: Elsever India private ltd; 2004. P. $311-15$.

[7]. Chamberlain's Symptoms and Signs in clinical medicine, 11 th Edition, E.L.B.S., (1992).

[8]. Hall \& Colman. Diseases of the nose, throat and ear, and head and neck. $14^{\text {th }}$ ed. Laurence Hunter Publisher; 1995. P. $97-98$.

[9]. Dr Hathiram BT, Dr Grewal DS. Ear, nose, throat simplified. Mumbai: Bhalain Book Depot. 1999. P. 234 - 237.

[10]. Gray. RF, Hawthoren, M. Synopsis of otolaryngology. $5^{\text {th }}$ ed. Elesevier, Indian edition; P. 346 - 47, $355-58$.

[11]. Allen J.H., Reprint Edition, The Chronic Miasm Psora and Psedopsora, B. Jain Publisher (P) Ltd., New Delhi, (1999).

[12]. Fergie WH. Essentials of Homoeopathic Prescribing. New Delhi: B Jain Publishers (P) Ltd. P. 3.

[13]. Allen J.H. The chronic miasms Psora and Sycosis. New Delhi: B Jain Publishers: (P) Ltd: 2002. P. 107, $172,188$.

[14]. Hahnemann Dr. S.C.F, The Chronic Disease and their Peculiar Nature and their Homoeopathic Cure, B Jain Publisher (P) Ltd., New Delhi, (2002). 
Distrution of Tonsillitis According Sex

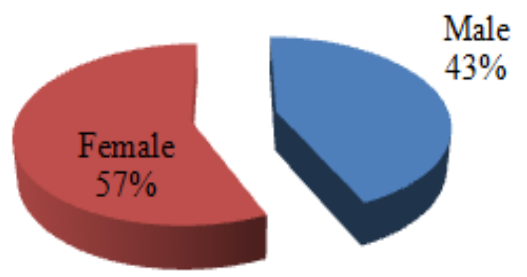

Distribution of Tonsillitis According To Age Group

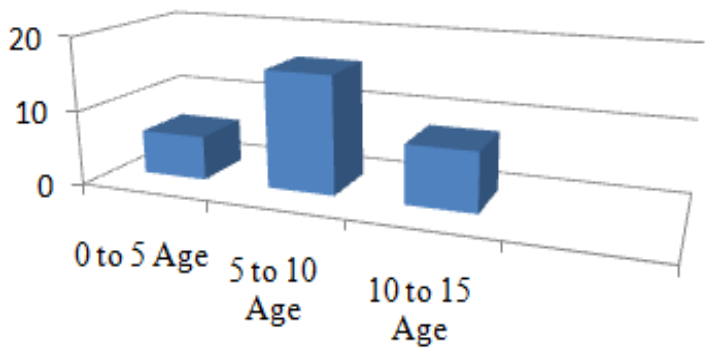

Distribution of Remedy Response in Both Sexes In Treatment of Tonsillitis

5

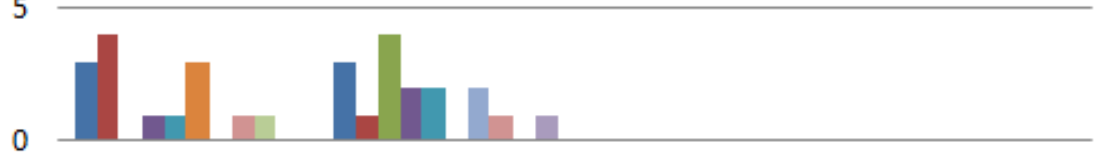

Male

Female

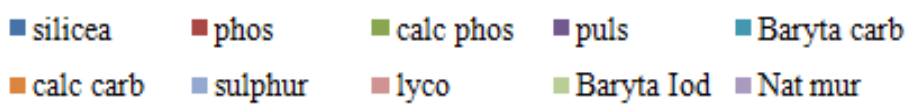

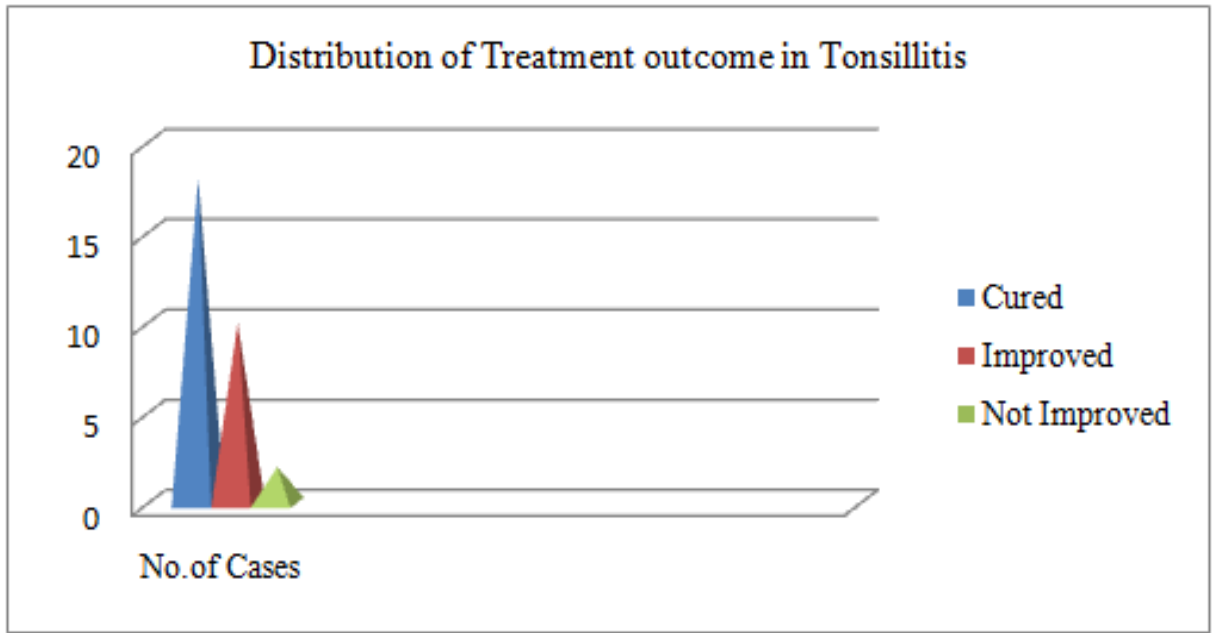


Distribution of Tonsillitis According to Sex

\begin{tabular}{|l|l|l|}
\hline Sex & No. Of Cases & Percentage (\%) \\
\hline Male & 13 & $43.33 \%$ \\
\hline Female & 17 & $56.66 \%$ \\
\hline Total & 30 & $100 \%$ \\
\hline
\end{tabular}

Distribution of Tonsillitis According to Age Group

\begin{tabular}{|l|l|l|}
\hline Age Group & No. Of Cases & Percentage (\%) \\
\hline $0-5$ & 6 & $20.00 \%$ \\
\hline $5-10$ & 16 & $53.33 \%$ \\
\hline $10-15$ & 8 & $26.66 \%$ \\
\hline Total & 30 & $100 \%$ \\
\hline
\end{tabular}

Distribution of Treatment Out Come in Tonsillitis

\begin{tabular}{|l|l|l|}
\hline Out come to Treatment & No. Of Cases & Percentage (\%) \\
\hline Cured & 18 & $60 \%$ \\
\hline Improved & 10 & $33 \%$ \\
\hline Not improved & 2 & $7 \%$ \\
\hline Total & 30 & $100 \%$ \\
\hline
\end{tabular}

Distribution of Drugs used in Treatment of Tonsillitis

\begin{tabular}{|l|l|l|}
\hline Drugs & No. Of Cases & Percentage\% \\
\hline Silicea & 6 & $20.00 \%$ \\
\hline Phosphorus & 5 & $16.6 \% 6$ \\
\hline Calcarea Phosphorica & 4 & $13.33 \%$ \\
\hline Baryta Carbonica & 3 & $10.00 \%$ \\
\hline Pulsatilla Pratensis & 3 & $10.00 \%$ \\
\hline Calcarea Carbonica & 3 & $10.00 \%$ \\
\hline Sulphur & 2 & $6.66 \%$ \\
\hline Lycopodium Clavatum & 2 & $6.66 \%$ \\
\hline Baryta Iodata & 1 & $3.33 \%$ \\
\hline Natrium Muriaticum & 1 & $3.33 \%$ \\
\hline Total & 30 & $100 \%$ \\
\hline
\end{tabular}

